\title{
Microstructure and Mechanical Properties of a Spray-Formed Superalloy
}

\author{
Fuwei Kang $\cdot$ Fuyang Cao $\cdot$ Xuemin Zhang $\cdot$ Hongyan Yue $\cdot$ Yicheng Feng
}

Received: 23 December 2013/Revised: 6 February 2014/Published online: 15 August 2014

(C) The Chinese Society for Metals and Springer-Verlag Berlin Heidelberg 2014

\begin{abstract}
The microstructural evolution and mechanical properties of a spray-formed superalloy were studied in this paper. Based on a better understanding of the microstructural evolution of the spray-formed superalloy during solution treatment, an optimum solution treatment process was obtained, namely, at $1,140{ }^{\circ} \mathrm{C}$ for $6 \mathrm{~h}$, and air cooling (AC). The effects of the ageing treatments on the mechanical properties of the post-solution-treated spray-formed superalloy were evaluated using ageing harden curves and tensile testing. The results indicated that the maximum hardness value was achieved at $850{ }^{\circ} \mathrm{C}$ for $8 \mathrm{~h}, \mathrm{AC}$. Due to co-precipitation of primary and secondary $\gamma^{\prime}$ precipitates during the heat treatment, the spray-formed superalloy obtained an excellent combination of yield strength ( $\mathrm{YS}=1,110 \mathrm{MPa}$ ), ultimate tensile strength (UTS $=1,503 \mathrm{MPa}$ ), ductility (elongation, $\mathrm{EL}=21 \%$ ) and excellent stress rupture properties at $650{ }^{\circ} \mathrm{C}$ (UTS $=1,209 \mathrm{MPa}, \mathrm{EL}=15.8 \%$ ). The heat treatment also improved the rupture life at $650{ }^{\circ} \mathrm{C} / 950 \mathrm{MPa}$ and $750{ }^{\circ} \mathrm{C} /$ $539 \mathrm{MPa}$ up to $140 \mathrm{~h}$ without rupturing. The tensile-fractured surfaces exhibit ductile transgranular failure feature. The optimum heat treatment process was determined to be $1,140{ }^{\circ} \mathrm{C} / 6 \mathrm{~h}+850^{\circ} \mathrm{C} / 8 \mathrm{~h}+\mathrm{AC}$.
\end{abstract}

\section{KEY WORDS: Spray-formed superalloy; Microstructure; Ageing harden; Mechanical properties}

\section{Introduction}

Nickel-based superalloys are widely used for high-performance applications such as discs and blades of either aircraft engines or land-based gas turbines due to their excellent mechanical properties at elevated temperatures and good corrosion resistance. The investigated superalloy is a representative precipitation-strengthened nickel-base superalloy, with more alloying elements such as $\mathrm{Cr}$, Co and

Available online at http://link.springer.com/journal/40195

F. Kang $(\bowtie) \cdot$ X. Zhang $\cdot$ H. Yue $\cdot$ Y. Feng School of Materials Science and Engineering, Harbin University of Science and Technology, Harbin 150040, China e-mail: fuwei_kang@163.com

F. Cao

School of Materials Science and Engineering, Harbin Institute of Technology, Harbin 150001, China
Mo on the base of GH742 alloy and has a high fraction of $\gamma^{\prime}$ precipitates $(\sim 65 \mathrm{vol} \%)$.

Cracking often occurs during forging of high alloying superalloys by the conventional ingot metallurgy plus forging processes due to the severe segregation of alloying elements. However, processing of the alloy by powder metallurgy has the disadvantages of powder oxidizsation and complex processing procedure.

Spray forming may be regarded as an alternative process route of manufacturing nickel-base superalloys. It has been well documented in this process, droplets are atomized from a molten metal, cooled by a high velocity inert gas such as nitrogen and finally deposited on a substrate to build up a rapidly solidified material $[1,2]$. The spray-forming process leads to a considerable reduction of processing steps for materials. Owing to the non-equilibrium solidification conditions, spray-formed materials possess a fine, uniform and equiaxed microstructure, with low microsegregation, high solubility and excellent workability [3-8]. It is reported that 


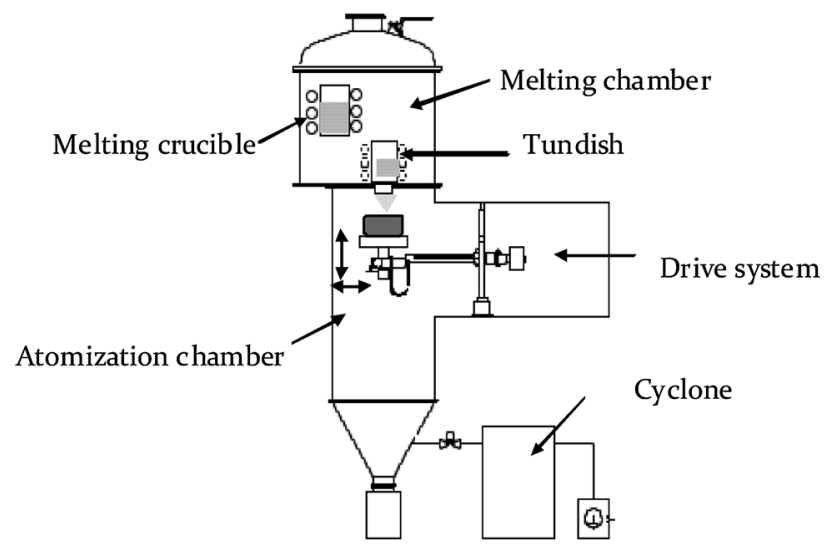

Fig. 1 Schematic diagram of spray-forming set-up

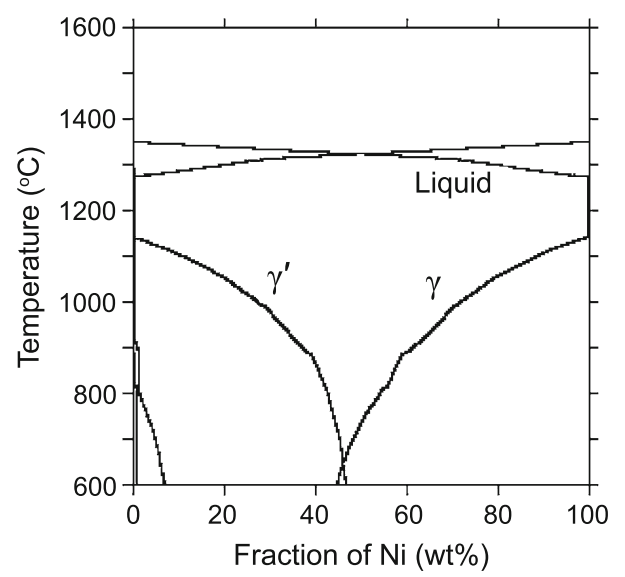

Fig. 2 Calculated phase diagram of the as-HIPed spray-formed superalloy

the process is particularly suited for the processing of highly alloyed superalloys, because significant structural refinement of superalloys normally cannot be achieved by either conventional casting processes or hot working.

Although many investigations have been undertaken on the synthesis of spray-formed superalloys [9-12], limited work has been dedicated to their heat treatment characteristics until now [13-15].

The aim of the present study was to investigate the microstructure characteristics in solution and ageing treatment conditions of the spray-formed nickel-base superalloy. Mechanical properties in various heat treatment conditions were also discussed.

\section{Experimental}

The spray-forming experiments were carried out by ultrasonic atomization spray-forming set-up, as shown in Fig. 1.
The alloy was atomized by nitrogen with the pressure of 2.5 $\mathrm{MPa}$, and deposited onto a stainless steel substrate rotating at $60 \mathrm{r} / \mathrm{min}$. The distance from the atomization nozzle to the substrate was $500 \mathrm{~mm}$. the gas-to-melt flow ratio was about $1.43 \mathrm{~m}^{3} / \mathrm{kg}$. The size of the spray-formed billet was $200 \mathrm{~mm}$ in height and $180 \mathrm{~mm}$ in diameter. The composition (in wt \%) of the alloy is Cr 11.06, Mo 4.55, W 2.64, Ti 2.59, Nb 2.74, Co 14.4, Al 3.12 and the balance of Ni. To improve the density of the billet, hot isostatic pressing (HIPing) was introduced at $1,130{ }^{\circ} \mathrm{C}, 140 \mathrm{MPa}$, for $2 \mathrm{~h}$. The relative densities of the billet were measured based on Archimedes' law. For the present investigated alloy, the relative densities were increased from 96.1 to 99.6\% of the theoretical density after HIPing.

Figure 2 plots the calculated phase diagram of the sprayformed superalloy through thermal-calc software. It is shown that the $\gamma^{\prime}$ precipitates dissolve into $\gamma$ matrix at about $1,130{ }^{\circ} \mathrm{C}$.

Solutionizing treatment and ageing treatment are the two types of heat treatment employed in this work. The solutionizing treatments were operated at $1,120-1,150{ }^{\circ} \mathrm{C}$ for $2-6 \mathrm{~h}$, while the ageing treatments were operated at $750-850{ }^{\circ} \mathrm{C}$ for $4-12 \mathrm{~h}$. Two cooling processes were adopted, named as water quenching (W.Q.) and air cooling (AC). The Vickers hardness tests were employed to measure the hardness of samples after heat treatment with a load of $9.8 \mathrm{~N}$ and a loading time $10 \mathrm{~s}$. At least three measurements were taken for each data point.

For microstructural examinations, the samples were polished and etched by the Marble reagent and then analysed by an Olympus optical GX-71-6230A microscope. Philips Quanta 200 scanning electron microscope (SEM) was used to examine the characteristics of $\gamma^{\prime}$ precipitates present in the microstructure and tensile rapture surface. Quantitative measurements of $\gamma^{\prime}$ precipitates size were made directly on the SEM micrographs using a semiautomatic image analyzer. Tensile tests were conducted at room temperature and $650{ }^{\circ} \mathrm{C}$, respectively, using an Instron-1186 universal testing machine with initial strain rate of $10^{-3} / \mathrm{s}$. The stress rupture tests were performed at $650{ }^{\circ} \mathrm{C} / 950 \mathrm{MPa}$ and $750{ }^{\circ} \mathrm{C} / 539 \mathrm{MPa}$, respectively.

\section{Results and Discussion}

\subsection{Effect of Solution Treatments on Microstructure}

Figure 3 shows the microstructures of as-HIPed sprayformed superalloy, which is composed of austenitic matrix with an average grain size of about $40 \mu \mathrm{m}$ (Fig. 3a). SEM examination of the specimen revealed coarse cuboidal and cinquefoil $\gamma^{\prime}$ precipitates in the grains interior, a dispersion 

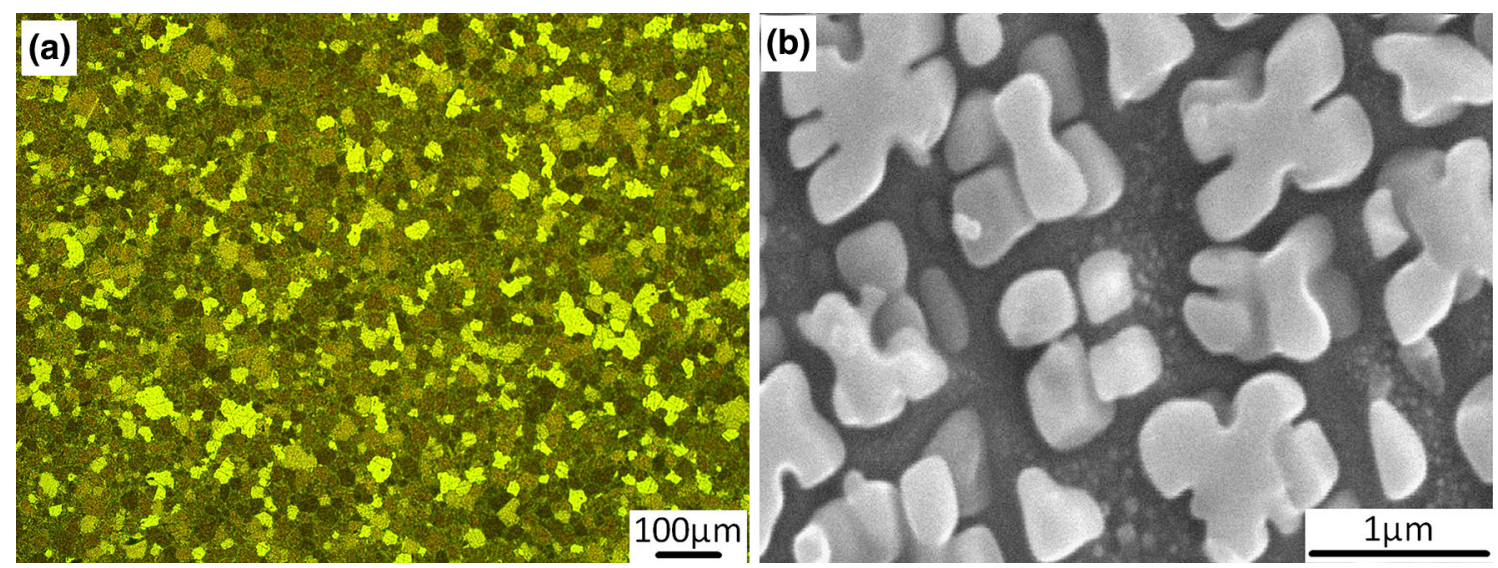

Fig. 3 Optical image a, SEM image b showing the microstructures of the as-HIPed spray-formed alloy
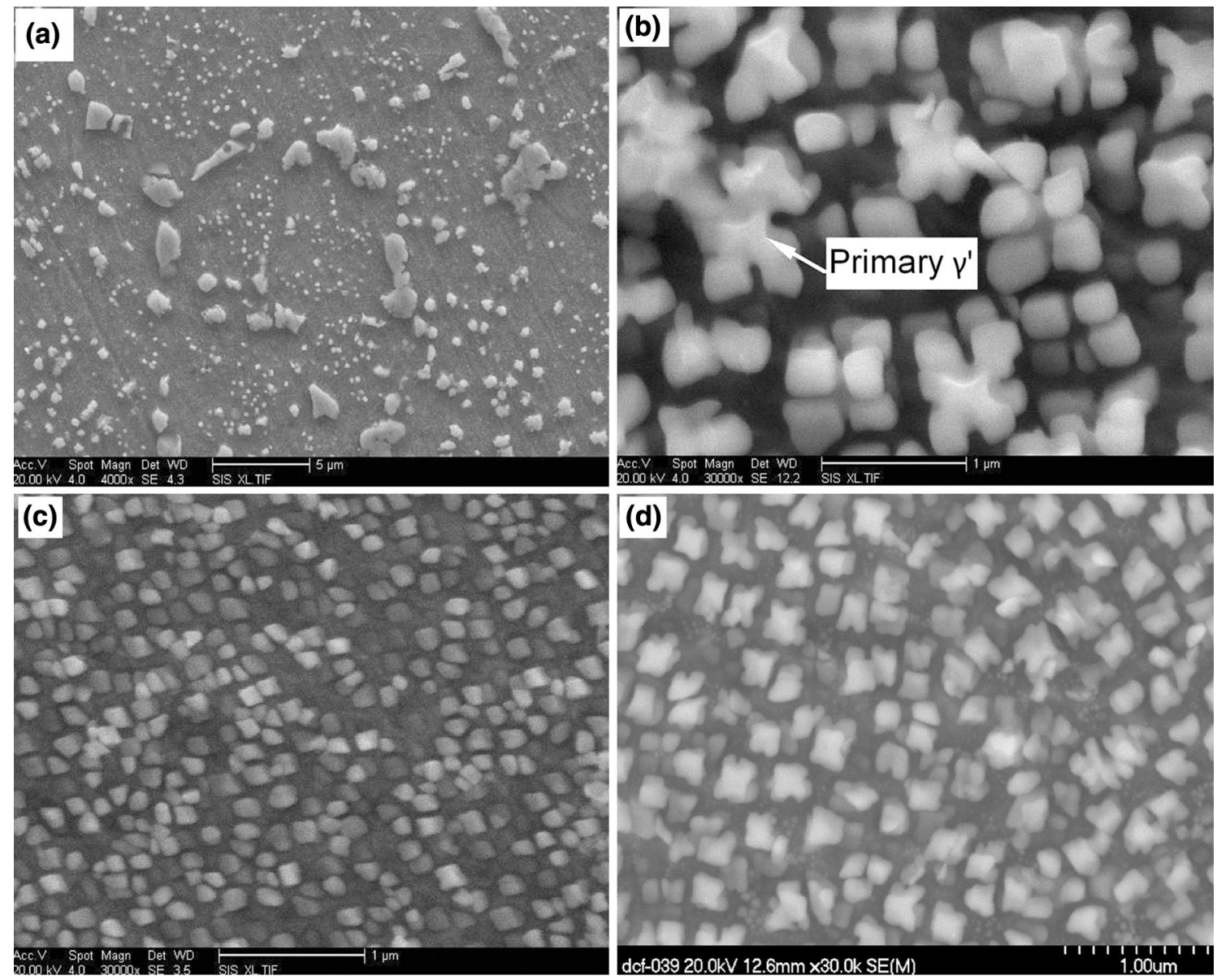

Fig. 4 SEM micrographs of spray-formed superalloy under different solution treatment conditions: a $1,120{ }^{\circ} \mathrm{C} / 2 \mathrm{~h}+\mathrm{WQ}$, b $1,130{ }^{\circ} \mathrm{C} /$ $6 \mathrm{~h}+\mathrm{AC}, \mathbf{c} 1,140{ }^{\circ} \mathrm{C} / 6 \mathrm{~h}+\mathrm{AC}, \mathbf{d} 1,150{ }^{\circ} \mathrm{C} / 4 \mathrm{~h}+\mathrm{AC}$

of extremely fine particles perceived in the $\gamma$ matrix, as shown in Fig. 3b.

Solution heat treatment was employed to dissolve the coarse $\gamma^{\prime}$ precipitates formed during solidification and to reduce the degree of chemical segregation for the spray- formed superalloy. It is indicated in Fig. 4 that the precipitation of $\gamma^{\prime}$ is strongly dependent on solution temperature and cooling rate. $\gamma^{\prime}$ precipitates with different sizes were obtained for the sample which was water quenched (WQ) after solution treatment at $1,120^{\circ} \mathrm{C}$ for $2 \mathrm{~h}$, as 


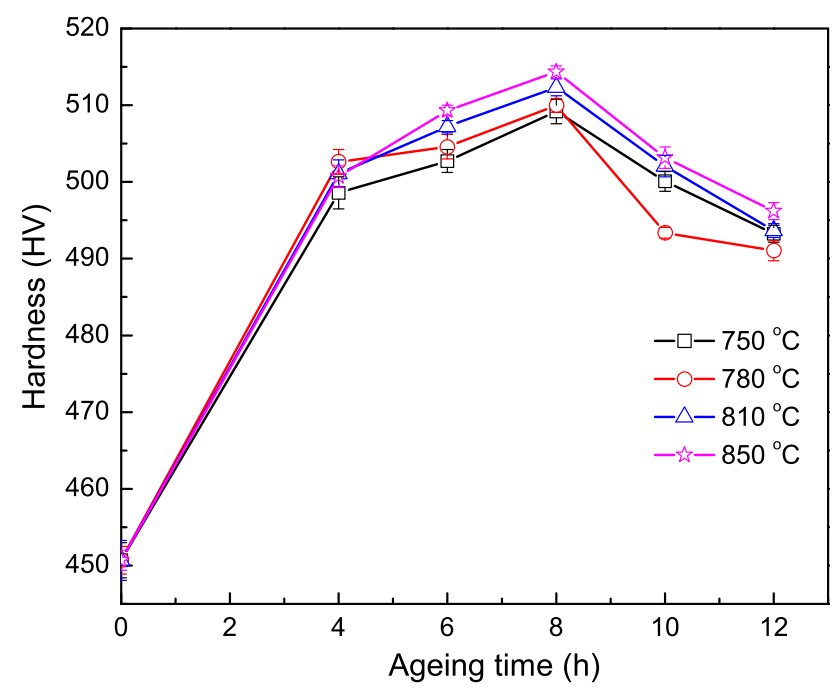

Fig. 5 Hardness of the post-solution-treated spray-formed superalloy under different ageing time and ageing temperatures

shown in Fig. 4a. Large size $\gamma^{\prime}$ precipitates with an irregular shape, discontinuously distributed along the grain boundary, whereas medium size $\gamma^{\prime}$ precipitates distributed in the grains. According to the results of Fig. 2, the $\gamma^{\prime}$ precipitates dissolve into $\gamma$ matrix at about $1,130{ }^{\circ} \mathrm{C}$. At solution temperature of $120{ }^{\circ} \mathrm{C}$, the $\gamma^{\prime}$ precipitates could not sufficiently dissolve, very fine $\gamma^{\prime}$ precipitated in the grains during solution cooling from the solution treatment. In Fig. 4a-d, although the amount and size of $\gamma^{\prime}$ precipitates are less by WQ than those by AC, WQ does not completely hinder the precipitating of $\gamma^{\prime}$ due to the highly solid solubility of $\mathrm{Ti}$ and $\mathrm{Al}$ elements in spray-formed superalloy. As a result, the precipitating drive force of $\gamma^{\prime}$ precipitates increases, and the strain energy and interface energy of nucleating decrease due to the coherence between $\gamma$ and $\gamma^{\prime}$ precipitates. It is in good agreement with the result of literature [16].

With the increase of solution temperature from 1,130 to $1,150{ }^{\circ} \mathrm{C}$, as shown in Fig. $4 \mathrm{~b}, \mathrm{c}, \mathrm{d}$, the primary $\gamma^{\prime}$ precipitates gradually disappeared while the size of secondary $\gamma^{\prime}$ precipitates gradually increased. A significant shape changes of the $\gamma^{\prime}$ precipitates from cuboidal and petals (Fig. 4b) to similar spherical (Fig. 4c) were observed. The above results demonstrate that the optimum solution treatment process $1,140{ }^{\circ} \mathrm{C} / 6 \mathrm{~h}+\mathrm{AC}$ for the spray-formed superalloy.

\subsection{Effect of Ageing Treatments on Hardness and the Size of $\gamma^{\prime}$ Precipitates}

The Vickers hardness is plotted against ageing time at various ageing temperatures for the post-solution treated

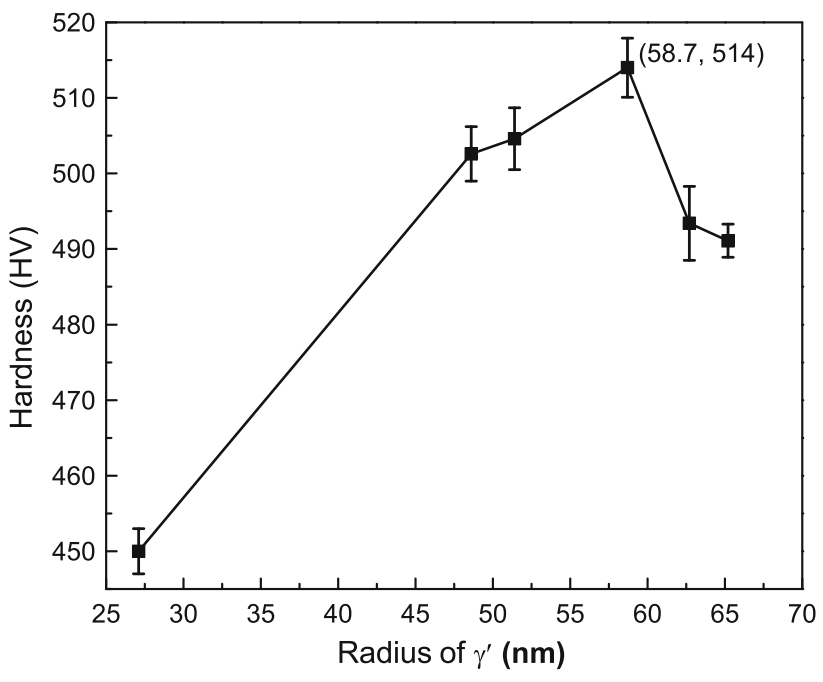

Fig. 6 Hardness versus radius of $\gamma^{\prime}$ precipitates of spray-formed superalloy under the heat treatment condition of $1,140{ }^{\circ} \mathrm{C} /$ $6 \mathrm{~h}+850{ }^{\circ} \mathrm{C} / 8 \mathrm{~h}+\mathrm{AC}$

alloy in Fig. 5. The hardness of the matrix increases with ageing time before reaching a peak value obtained at $8 \mathrm{~h}$ for all testing conditions, then the hardness value decreases with ageing time, as shown in Fig. 5. Generally, the higher the hardness of alloys the higher is the strength of alloys. The highest strength is obtained when ageing at $850{ }^{\circ} \mathrm{C}$ for $8 \mathrm{~h}$.

Dislocation/particle interaction mechanisms have been used to interpret the peak ageing hardness value. When the size of $\gamma^{\prime}$ precipitates is less than the critical size, $\gamma^{\prime}$ precipitates exhibit spherical shape, and $\gamma / \gamma^{\prime}$ has coherent relationship. The dislocations cut through the $\gamma^{\prime}$ precipitates, which leads to the increase in hardness and strength. However, if the size of $\gamma^{\prime}$ precipitates is larger than the critical size, $\gamma^{\prime}$ precipitates exhibit cuboidal and polygonal shape, the coherent level is less between $\gamma$ and $\gamma^{\prime}$ precipitates. Dislocations bypass through the $\gamma^{\prime}$ precipitates. Subsequently, with the increase of $\gamma^{\prime}$ precipitates size, the distance between precipitates becomes larger, and then dislocations can easily bypass through $\gamma^{\prime}$ precipitates, leading to the decrease in hardness and strength.

According to the mechanism of order strengthening by dislocation cutting particle proposed by Gleiter et al. [17], the shear stress can be expressed as follows:

$\tau_{\mathrm{c}}=0.28 v_{\mathrm{APB}}^{\frac{3}{2}} f^{\frac{1}{3}} G^{-\frac{1}{2}} b^{-2} r^{\frac{1}{2}}$,

where $v_{\mathrm{APB}}$ is the anti-phase boundary energy, $f$ is the volume fraction of $\gamma^{\prime}$ precipitates, $G$ is the shear module, $b$ is the Burgers vector, and $r$ is the average radius of $\gamma^{\prime}$ precipitates. 

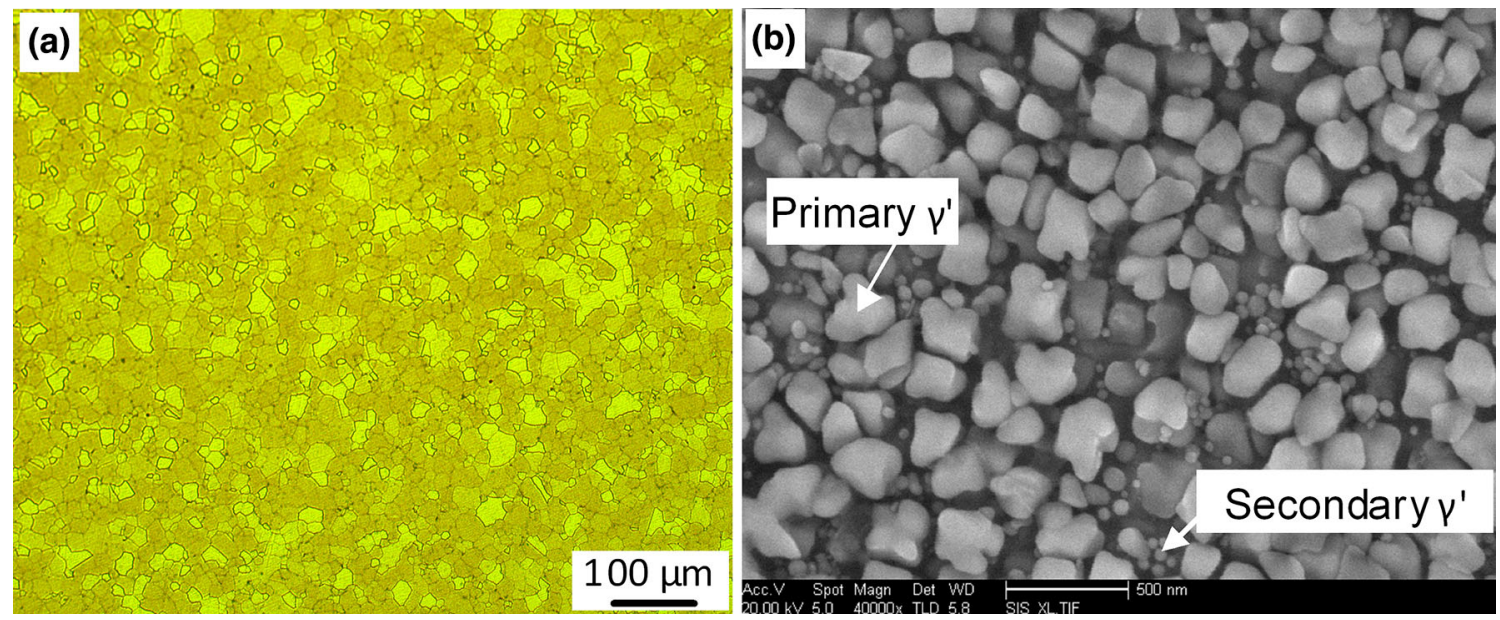

Fig. 7 Optical image a, SEM image b showing the microstructures of the spray-formed superalloy the heat treatment condition of $1,140{ }^{\circ} \mathrm{C} /$ $6 \mathrm{~h}+850{ }^{\circ} \mathrm{C} / 8 \mathrm{~h}+\mathrm{AC}$

The critical shear stress expressed by Orowan by-passing through mechanism is as follows [18] :

$\tau_{\mathrm{oc}}=\frac{0.4 G b}{\pi \lambda} \frac{1}{\sqrt{1-v}} \ln \left(\frac{2 r_{s}}{b}\right)$,

where $\lambda$ is the distance between $\gamma^{\prime}$ precipitates expressed by $\lambda=(\sqrt{(\pi / f)}-2) \cdot r_{\mathrm{s}}, r_{\mathrm{s}}$ is the average radius of $\gamma^{\prime}$ precipitates on the slipping surface expressed by $r_{\mathrm{s}}=r \sqrt{(2 / 3)}$, and $v$ is the Poisson's ratio.

The critical radius of $\gamma^{\prime}$ precipitates can be determined by $\tau_{\mathrm{c}}=\tau_{\mathrm{oc}}$ at the region of 'cutting' and 'bypassing'. For the investigated alloy, the parameters in the Eqs. (1) and (2) can be obtained in literature [19], namely $v_{\mathrm{APB}}=0.12 \mathrm{~J} /$ $\mathrm{m}^{2}, G=50 \mathrm{GPa}, b=0.22 \mathrm{~nm}, v=0.3, f=0.4$. The critical radius is calculated as $53.6 \mathrm{~nm}$. On the other hand, the critical radius was measured as $58.7 \mathrm{~nm}$, as shown in Fig. 6, which is a perfect match to the calculated one. It clearly shows the validity of dislocation/particle reaction mechanism. According to the above results, the heat treatment process of the spray-formed superalloy is determined to be $1,140{ }^{\circ} \mathrm{C} / 6 \mathrm{~h}+850{ }^{\circ} \mathrm{C} / 8 \mathrm{~h}+\mathrm{AC}$.

Figure 7 illustrates typical microstructures of the sprayformed superalloy obtained by the above optimum heat treatment process. The corresponding microstructures remain finer equiaxed grains after heat treatment as shown in Fig. 7a, which predicts that the alloy possesses good mechanical properties. Figure $7 \mathrm{~b}$ shows the SEM image of Fig. 7a counterpart, which consists of spherical $\gamma^{\prime}$ precipitates with different sizes. The formation of large size $\gamma^{\prime}$ precipitates (primary $\gamma^{\prime}$ ) was responsible for the precipitation of dissolved $\gamma^{\prime}$ precipitates during solution cooling, while small size ones (secondary $\gamma^{\prime}$ ) responsible for the precipitation of dissolved $\gamma^{\prime}$ precipitates during ageing cooling. Bimodal distributions of $\gamma^{\prime}$ precipitates can be observed in the heat treatment, as shown in Fig. 7b, beneficial to improve the mechanical properties of the nickelbase superalloy [20].

\subsection{Mechanical Properties of the Spray-Formed Superalloy}

The room/high-temperature tensile properties of the heattreated spray-formed superalloy are presented in Table 1 . The tensile properties of the wrought (cast + forged) superalloy has also been listed for comparison. It indicates that the yield stress (YS $=1,110 \mathrm{MPa}$ ), ultimate tensile stress $(\mathrm{UTS}=1,503 \mathrm{MPa})$ and elongation $(\mathrm{EL}=21 \%)$ of the spray-formed superalloy at room temperature are higher than those of the wrought alloy. It also indicates that the instant tensile properties (UTS $=1,209 \mathrm{MPa}$, $\mathrm{EL}=15.8 \%)$ at $650{ }^{\circ} \mathrm{C}$ are higher than those of counterpart. The creep rupture life (more than $140 \mathrm{~h}$ ) of the sprayformed superalloy at 650 and $750{ }^{\circ} \mathrm{C}$ are also longer than those of the wrought alloy.

Generally, the mechanical properties of superalloy are strongly dependent on the size and morphology of the $\gamma^{\prime}$ precipitates [21]. In order to explain the reason, it is necessary to consider the influence of the $\gamma^{\prime}$ precipitates on the mechanical properties. The size and morphology of the $\gamma^{\prime}$ precipitates changed after heat treatment (Fig. 7b). It is suggested that the co-precipitation of primary $\gamma^{\prime}$ precipitates, secondary $\gamma^{\prime}$ precipitates in the heat treatment condition promotes an increase in strength. The increased elongation values could be attributed to the precipitation of coherent $\gamma^{\prime}$ and $\gamma$ phases, which contributes to homogenise the slip process to an increase in the elongation and the ultimate tensile strength. The room/high-temperature tensile-fractured surfaces of the spray-formed superalloy are 
Table 1 Comparison of mechanical properties of spray-formed and conventional Samples at different conditions

\begin{tabular}{|c|c|c|c|c|c|c|c|}
\hline \multirow[t]{2}{*}{ Sample } & \multicolumn{2}{|c|}{ UTS (MPa) } & \multirow[t]{2}{*}{ YS at RT (MPa) } & \multicolumn{2}{|c|}{ EL (\%) } & \multicolumn{2}{|l|}{ Rupture life (h) } \\
\hline & RT & $650{ }^{\circ} \mathrm{C}$ & & RT & $650{ }^{\circ} \mathrm{C}$ & $650^{\circ} \mathrm{C} / 950 \mathrm{MPa}$ & $750{ }^{\circ} \mathrm{C} / 539 \mathrm{MPa}$ \\
\hline Spray formed & 1,503 & 1,209 & 1,110 & 21 & 15.8 & $>140$ & $>140$ \\
\hline Wrought [20] & 1,275 & 1,150 & 8,53 & 14 & 14 & 100 & 100 \\
\hline
\end{tabular}

$R T$ room temperature
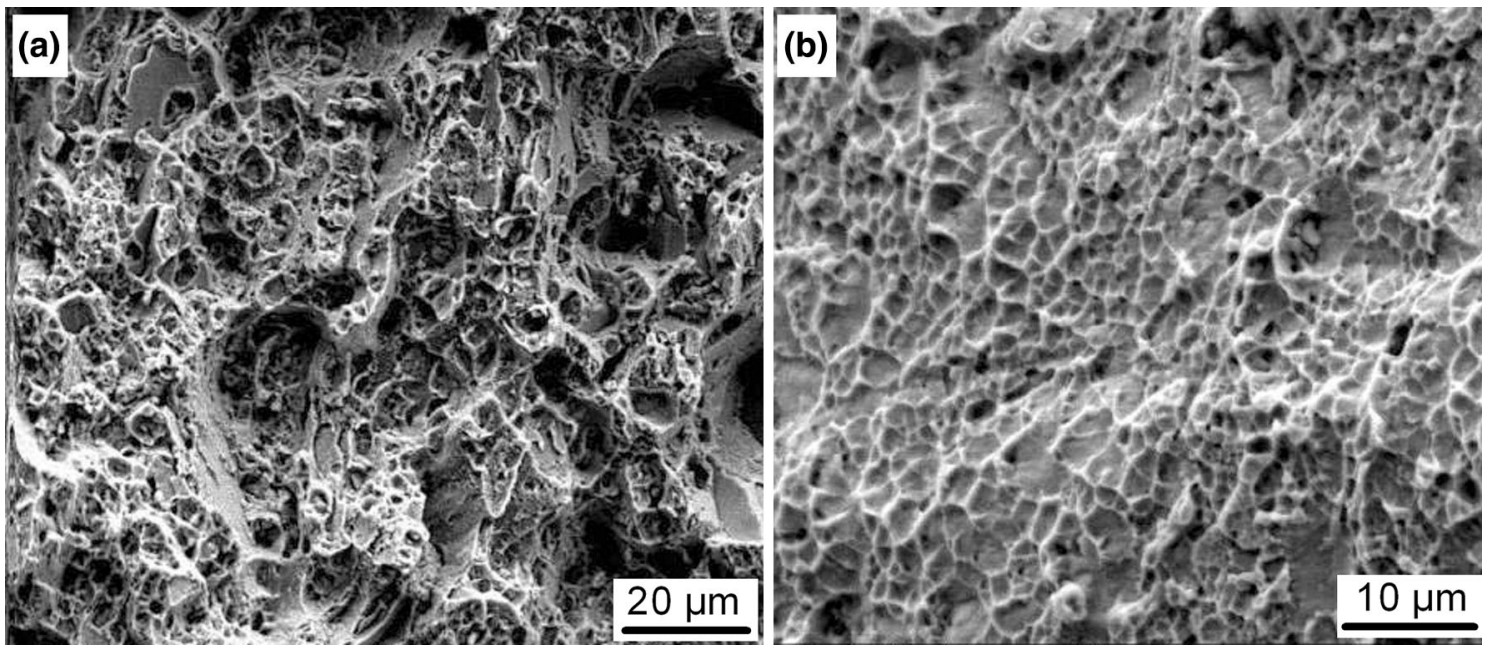

Fig. 8 SEM images of heat treatment spray-formed superalloy after tensile tests at room temperature $\mathbf{a}, 650{ }^{\circ} \mathrm{C} \mathbf{b}$

presented in Fig. 8. Fine dimples on the fracture surfaces of the alloy at room temperature shown in Fig. 8a indicate void coalescence and ductile transgranular fracture. The fractograph of the $650{ }^{\circ} \mathrm{C}$ tensile samples which is shown in Fig. $8 \mathrm{~b}$ reveals the same finer dimples that tested at room temperature (Fig. 8a), suggesting a ductile transgranular failure mode, which is consistent with the good ductility of the alloy at both the temperatures.

\section{Conclusions}

In the present study, the microstructure characteristics and mechanical properties of a spray-formed nickel-base superalloy have been investigated. The following conclusions can be drawn:

(1) The optimum solution treatment process is determined to be $1140{ }^{\circ} \mathrm{C} / 6 \mathrm{~h}+\mathrm{AC}$, at which more amount and bimodal distribution of $\gamma^{\prime}$ precipitates are obtained.

(2) The peak hardness values were obtained at $850^{\circ} \mathrm{C}$ for $8 \mathrm{~h}, \mathrm{AC}$. The measured value of $\gamma^{\prime}$ critical radius is almost equal to the calculated one. When the $\gamma^{\prime}$ radius is less than the critical value, the dislocations cut through the $\gamma^{\prime}$ precipitates, resulting in an increase in strength. When the $\gamma^{\prime}$ radius is larger than the critical value, the dislocations are by-passing the $\gamma^{\prime}$ precipitates, and the strength is decreased.
(3) The optimum heat treatment process is proposed as $1,140{ }^{\circ} \mathrm{C} / 6 \mathrm{~h}+850{ }^{\circ} \mathrm{C} / 8 \mathrm{~h}+\mathrm{AC}$ for this spray-formed superalloy. The mechanical properties of the heat-treated superalloy are determined as UTS $=1,503 \mathrm{MPa}$, $\mathrm{YS}=1,110 \mathrm{MPa}, \mathrm{EL}=21 \%$. The instant tensile properties as UTS $=1,209 \mathrm{MPa}, \mathrm{EL}=15.8 \%$ at $650{ }^{\circ} \mathrm{C}$. The high rupture life of longer than $140 \mathrm{~h}$ can be achieved at $650{ }^{\circ} \mathrm{C} / 950 \mathrm{MPa}$ and $750{ }^{\circ} \mathrm{C} / 539 \mathrm{MPa}$. These properties are superior to wrought superalloy counterpart.

(4) The excellent mechanical properties are attributed to the co-precipitation of primary and secondary $\gamma^{\prime}$ precipitates after heat treatment. The tensile-fracture surfaces are characterised by fine dimples at room/high-temperature, exhibiting a ductile transgranular rupture mode.

Acknowledgments This work was financially supported by the Heilongjiang Provincial Natural Science Foundation of China (No. 201107).

\section{References}

[1] P.S. Grant, Prog. Mater. Sci. 35, 497 (1995)

[2] E.J. Lavernia, Y. Wu, Spray Atomization and Deposition (Wiley, New York, 1996)

[3] B. Cantor, K.H. Baik, P.S. Grant, Prog. Mater. Sci. 42, 373 (1997) 
[4] J.G. Zhang, H.S. Shi, D.S. Sun, J. Mater. Process. Tech. 138, 357 (2003)

[5] G.Q. Zhang, H. Yuan, D.L. Jiao, Z. Li, Y. Zhang, W.Z. Li, Mater. Sci. Eng. A 558, 566 (2012)

[6] H. Godinho, A.L.R. Beletati, E.J. Giordano, C. Bolfarini, J. Alloys Compd. 586, S139 (2014)

[7] E.M. Mazzer, C.R.M. Afouso, M. Galano, C.S. Kiminami, C. Bolfarini, J. Alloys Compd. 579, 169 (2013)

[8] Y. Xu, C.C. Ge, Q. Shu, J. Iron steel Res. 20(4), 59 (2013)

[9] Z. Li, G.Q. Zhang, Z.H. Zhang, S.F. Tian, Acta Metall. Sin. (Engl. Lett.) 17, 205 (2004)

[10] F.W. Kang, J.F. Sun, G.Q. Zhang, Z. Li, J. Mater. Sci. Technol. 25, 373 (2009)

[11] J.F. Sun, J. Shen, Acta Metall. Sin. (Engl. Lett.) 13, 800 (2000)

[12] M.D. Barratt, A.L. Dowson, M.H. Jacobs, Mater. Sci. Eng. A 383, 69 (2004)
[13] H. Yuan, Z. Li, G.Q. Zhang, Mater. Eng. 1, 61 (2008)

[14] W.Y. Xu, Z. Li, H. Yuan, Y. Zhang, G.Q. Zhang, J. Aeronaut. Mater. 30, 7 (2010). (in Chinese)

[15] F.W. Kang, J.F. Sun, G.Q. Zhang, Z. Li, H.F. Ao, J. Shen, Rare Met. Mater. Eng. 36, 1205 (2007). (in Chinese)

[16] W.Y. Xu, Z. Li, H. Yuan, G.Q. Zhang, Rare Mets. 30, 392 (2011)

[17] E. Nembach, Mater. Sci. Technol. 4, 268 (1985)

[18] E. Nembach, Particle Strengthening of Metals and Alloys (Wiley, New York, 1996), p. 102

[19] M. Heilmaier, U. Leetz, B. Reppich, Mater. Sci. Eng. A 319-321, 375 (2001)

[20] H. Monajati, M. Jahazi, R. Bahrami, S. Yue, Mater. Sci. Eng. A 373, 286 (2004)

[21] A.M. Brass, D. Roux, J. Chene, Mater. Sci. Eng. A 323, 97 (2002) 